\title{
TQM on the Status of Sports in Sirsa and Bhiwani
}

\author{
Charan Singh, MonikaVerma
}

\begin{abstract}
Technology has a very sound impact on human being today. Our life is totally dependent and revolving around technology. We cannot think of our present life without technology and hence there is a substantial influence of modern technology on human lives. We are not using our muscles for every work as work is becoming more and more automatic due to technology. Our muscles on which once upon a time we used to depend oncompletely for existence, are now used for less and less with inexorable results. A number of research works has been done in various fields like medicine, psychology and physiology, to prove that moving the muscles for work have a number of benefits and due to technology we are making our body lazy and defective. However, very less have been made to the fact that exercise with associated development of fitness has far reaching effects on vigorous bodily processes and upon the functional realization of one's progress and competencies. The present paper is designed to study the TQM on the status of sports in Sirsa and Bhiwani.
\end{abstract}

Keywords : TQM, Technology, Sustantial Influence.

\section{INTRODUCTION}

$\mathrm{H}$ ealth services embrace a large kind of quality aspects, all of that square measure vital. In medicinal services, the retailers are doctors, clinics, nurses, nursing homes, child care and hospitalsetc. as a result of they provide health services available as stipulated costs. Consumer is the customerwho purchases these health services at the specified costs. It should conjointly enclosed eminence of enactment that's openlylinked and strictly associated with attention like food, housing, welfare, protection, angle of workers, and alternative aspects that ascend in reference to hospitals and clinics. So, the time takes in to the fix an arrangement, delay time, services time, temporal order with relevance medical treatment and surgery.

- Worth of organization and executives

- Eminence of doctors

- Superiority of hospitalization

\section{Benefits of TQM}

TQM is helpful for numerous reasons in education and sports as mentioned below.

1. Improved aggressiveness.

2. Higher gain, higher returns, reduction in overhead.

3. inflated sales and market shares.

4. Increased initiate satisfaction and increase in no. of

Revised Manuscript Received on July 22, 2019

Dr. Charan Singh, Assistant Professor/ HOD, Department of Physical Education, Guru Kashi University Talwandi Sabo, Punjab, India.

Dr.MonikaVerma, Professor, Department of Physical Education, Ch. Devi lal University Sirsa trainee.

5. Improved price effectiveness, reduced cost.

6. Reduction of rejection, scrap and wastage transforming.

7. Higher management on processes.

8. No-hit new product launch.

9. Speedier new merchandise introduction, a lot of new models.

10. Reengineered method.

11. Improved productivity.

12. Interval reduction

\section{Value of Care}

The following 5 areas are considered:

- Physical infrastructure: problems embrace technology valuation, system assimilation, and alternative long-run queries relating to preservation of a prime quality physical plant, while not that prime quality health care is not possible.

- Professional infrastructure: High-grade health care relies upon the presence of well-trained, devoted, health care specialists and managers. Most ancient quality reassurance efforts have focused on preserving this energetic space. Instances embrace graduate medical education, continued medical education, ancient referee, and amenability with standards set by external restrictive bodies.

- Choice to treat: Unsuitable diagnosing will cause additional hospitalization and treatment. Recent analysis suggests that, inside some diagnoses and procedures, a considerable part of health care involvements an unsuitable. Inappropriate medical aid wastes resources associated damages patients - it is a nearly outstanding instance of quality waste and is of explicit significance to health care financiers.

- Manner of treatment: Several studies have incontestable an awfully great amount of variation in resource utilization to attain equivalent results for explicit diagnoses and procedures. Inappropriate variation, once identical outcomes are obtained, is a wonderful instance of productivity waste.

\section{STATEMENT OF THE PROBLEM}

Impact of total quality management on the status of sports in Haryana

\section{OBJECTIVES OF THE STUDY}

i. To study the commitment of coach towards all trainees of various institutes with regard to quality management in sports.

ii. To study the process of recruitment of trainees with regard to quality management in sports. 
iii. To study the quality improvement of team work with regard to quality management in sports.

iv. To study the culture of services provided by the institutions with regard to quality management in sports.

\section{HYPOTHESES OF THE STUDY}

i. There is no noteworthy difference between coaches and trainees opinion towards coaching quality provided by Sirsa and Bhiwani.

ii. There is no noteworthy difference between coaches and trainees opinion towards financial facility provided by Sirsa and Bhiwani.

iii. There is no noteworthy difference between coaches and trainees opinion towards health care services provided by Sirsa and Bhiwani.

iv. There is no substantial difference between coaches and trainees opinion towards food and nutrition services provided by Sirsa and Bhiwani.

v. There is no substantial difference between coaches and trainees opinion towards infrastructure and equipment facilities provided by Sirsa and Bhiwani.

vi. There is no substantial difference between coaches and trainees opinion towards administrative services provided by Sirsa and Bhiwani.

\section{ANALYSIS AND INTERPRETATION OF DATA}

The minimum and maximum scores acquired and also the range of scores were calculated and presented in Table: 1 to 6 The complete data of total quality management of Sirsa,Hisar and Bhiwanidistricts were arranged in a way that mean and standard deviation may be calculated and also the mean difference $\mathrm{MD}(\mathrm{m} 1-\mathrm{m} 2)$ and the calculation regarding ' $\mathrm{t}$ ' test. Each variables regarding to total quality management was tabulated. The tabulation was prepared for each total quality management variables separately. The calculations in connection with ' $t$ ' - test were also arranged for individual variable wise. The graph-pad statistical technique were followed to calculate the 't'-test. The value of calculated ' $t$ '-test was compared with the tabulated substantial value at .05 level of confidence with 95 degree of freedom.

The particulars for comparative mean value and SD values of Sirsaand Bhiwaniwere tabulated and the values of ' $t$ '-test with various step values were also presented in graph1 to 6 .

Table-I: Comparison of total quality management (coaching qualities) provided of sirsa and bhiwani districts

\begin{tabular}{|c|c|c|c|c|}
\hline Groups & Mean & S. D. & S.E.D. & 't' \\
\cline { 1 - 3 } Sirsa & 16.40 & 2.07 & \multirow{2}{*}{14.72} & \multirow{2}{*}{$2.096^{* *}$} \\
\hline Bhiwani & 15.32 & 2.60 & & \\
\hline
\end{tabular}

Value of Significance at .01 level -2.61

Value of Significance at .05 level -1.64

DF (Degree of Freedom) $\quad-118$

Total Sample (N) $\quad-120$

Table: 1 represent the mean value of coaches and trainers opinion of coaching qualities provided of Sirsa and Bhiwani district is 2.60 and 16.40 respectively and the SD value of coaches and trainers opinion of coaching qualities is 2.07 and 15.32 respectively. The standard error difference is also find out with the reading of 14.72 . The ' $t$ ' value is calculated as 2.096, which is not significant at .05 level of significance. Hence, there is no substantial difference between coaches and trainers opinion of coaching qualities provided of Sirsa and Bhiwani districts is accept.

It is stated that mean value of Sirsa district is 16.40 which is higher than mean value of Bhiwani regarding coaching qualities. Therefore, it is found that the coaching qualities providing for sports person in comparison to Sirsa and Bhiwani district, Sirsa district is higher comparison to the Bhiwani district.

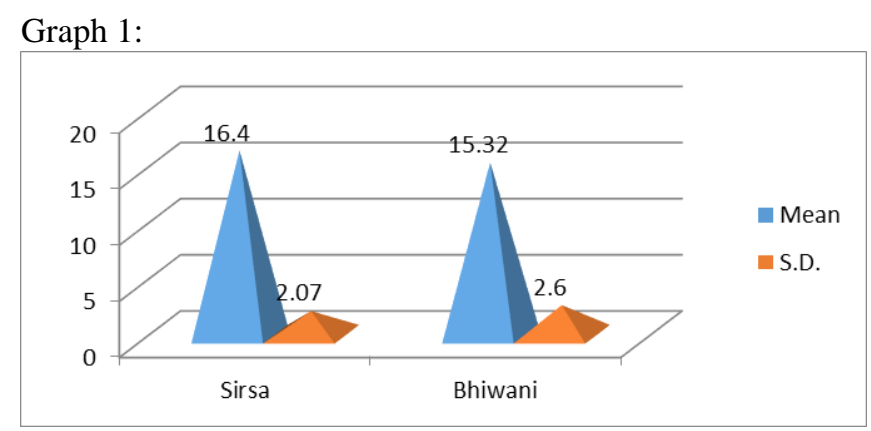

Table-II:Comparison of total quality management (finance facilities) provided of sirsa and bhiwani districts

\begin{tabular}{|c|c|c|c|c|}
\hline Groups & Mean & S. D. & $\begin{array}{c}\text { S.E. } \\
\text { D. }\end{array}$ & 't' \\
\cline { 1 - 3 } Sirsa & 11.83 & 10.7 & & \\
\cline { 1 - 3 } Bhiwani & 8 & 10.91 & 2.85 & $3.28^{*}$ \\
\hline
\end{tabular}

$\begin{array}{ll}\text { Value of Significance at } .01 \text { level } & -2.61 \\ \text { Value of Significance at } .05 \text { level } & -1.64 \\ \text { DF (Degree of Freedom) } & -118 \\ \text { Total Sample (N) } & -120\end{array}$

Table: 2 represent the mean value of coaches and trainers opinion of finance facilities of Sirsa and Bhiwani district is 11.83 and 8.00 respectively and the SD value of coaches and trainers opinion of finance facilities is 10.70 and 10.91 respectively. The standard error difference is also find out with the reading of 2.85. The ' $t$ ' value is calculated as 3.28 , which is significant at .05 level of significance. Hence, hypothesis there is no momentous difference between coaches and trainers opinion of finance facilities of Sirsa and Bhiwani districts is rejected.

It is stated that mean value of Sirsa district is 11.83 which is higher than mean value of Bhiwani regarding finance facilities. Therefore, it is found that the finance facilities for sports person in comparison to Sirsa and Bhiwani district, Sirsa district is higher comparison to the Bhiwani district.

Graph 2:

Published By:

Blue Eyes Intelligence Engineerin 


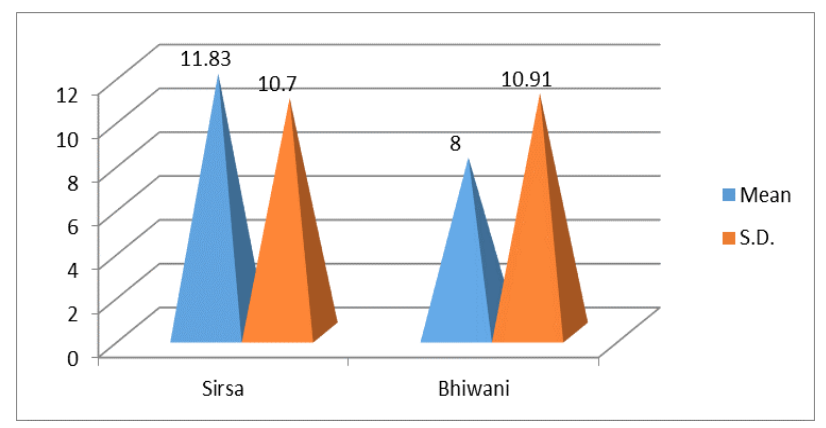

Table III:Comparison of total quality management (health care services) provided of sirsa and bhiwani districts

\begin{tabular}{|c|c|c|c|c|}
\hline Groups & Mean & S D & S.E.D. & 't'-Ratio \\
\hline Sirsa & 4.20 & 1.92 & \multirow{2}{*}{6.54} & \multirow{2}{*}{$3.21^{*}$} \\
\cline { 1 - 3 } Bhiwani & 13.60 & 6.01 & & \\
\hline
\end{tabular}

Value of Significance at .01 level - 2.61

Value of Significance at .05 level -1.64

DF (Degree of Freedom) $\quad-118$

Total Sample (N) $\quad-120$

Table: 3 represent the mean value of coaches and trainers opinion of health care of Sirsa and Bhiwani district is 4.20 and 13.60 respectively and the SD value of coaches and trainers opinion of health care is 1.92 and 6.01 respectively. The standard error difference is also find out with the reading of 6.54. The ' $t$ ' value is calculated as 3.21 which is greater than table value at .05 level of significance. Hence, hypothesis there is no substantial difference between coaches and trainers opinion of health care of Sirsa and Bhiwani districts is rejected.

It is stated that mean value of Bhiwani district is 13.60 which is higher than mean value of Sirsa regarding health care services. It is hereby stated that the health facility providing to the sports person in comparison to Sirsa and Bhiwani district, Bhiwani district is higher comparison to the Sirsa district.

Graph 3:

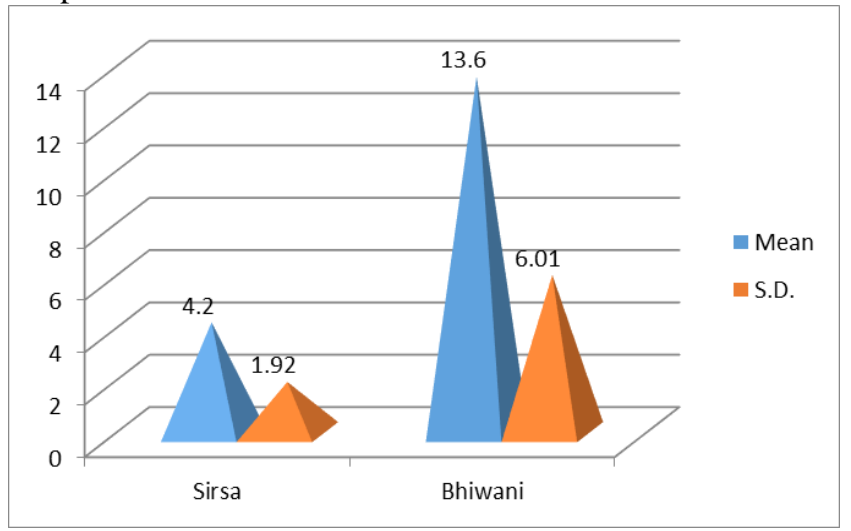

Table IV: Comparison of total quality management (food and nutrition) provided of sirsa and bhiwani districts.

\begin{tabular}{|c|c|c|c|c|}
\hline Groups & Mean & S D & S.E.D. & 't'-Ratio \\
\cline { 1 - 3 } SIRSA & 3 & 00 & \multirow{2}{*}{1.00} & \multirow{2}{*}{$3.00^{*}$} \\
\cline { 1 - 3 } BHIWANI & 6 & 1.41 & & \\
\hline
\end{tabular}

Value of Significance at .01 level - 2.61

Value of Significance at .05 level -1.64

DF (Degree of Freedom) $\quad-118$

Total Sample (N) - 120

Table: 4 represent the mean value of coaches and trainers opinion of Food and nutrition of Sirsa and Bhiwani district is 3 and 6 respectively and the SD value of coaches and trainers opinion of Food and nutrition is 0 and 1.41 respectively. The standard error difference is also find out with the reading of 1.00 and the ' $t$ ' value is calculated as 3.00 , which is significant at .05 level of significance. Hence, hypothesis there is no substantial difference between coaches and trainers opinion of Food and nutrition of Sirsa and Bhiwani districts is rejected.

It is stated that mean value of Bhiwani district is 6 which is higher than mean value of Sirsa regarding food and nutrition facilities for sports person. It is hereby stated that the food and nutrition facilities for sports person in comparison to Sirsa and Bhiwani district, Bhiwani district is higher comparison to the Sirsa district.

Graph 4:

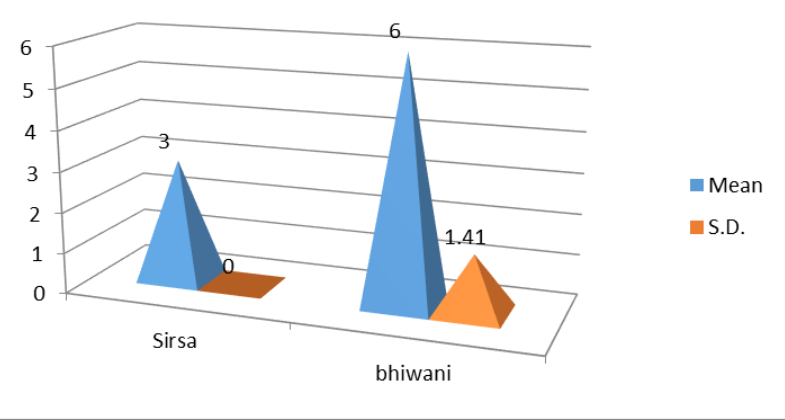

Table-V: Comparison of total quality management (infrastructure and equipments facilities) provided of sirsa and bhiwani districts

\begin{tabular}{|c|c|c|c|c|}
\hline Groups & Mean & S. D. & S.E.D. & 't'-Ratio \\
\cline { 1 - 3 } Sirsa & 5.50 & 4.94 & \multirow{2}{*}{4.00} & \multirow{2}{*}{$3.50 *$} \\
\cline { 1 - 3 } Bhiwani & 19.50 & 10.60 & & \\
\hline
\end{tabular}

Value of Significance at .01 level - 2.61

Value of Significance at .05 level - 1.64

DF (Degree of Freedom) - $\quad-118$

Total Sample (N) $\quad-120$

Table: 5 represent the mean value of coaches and trainers opinion of infrastructure and equipments facilities of Sirsa and Bhiwani district is 5.50 and 19.50respectively and the SD value of coaches and trainers opinion regarding Infrastructure and equipments facilities is 4.94 and 10.60 respectively. The 
standard error difference is also find out with the reading of 4.00. The ' $t$ ' value is calculated as 3.50, which is significant at .05 level of significance. Hence, hypothesis there is no momentous difference between coaches and trainers opinion of infrastructure and equipments facilities of Sirsa and Bhiwani districts is rejected.

It is stated that mean value of Bhiwani district is 19.50 which is higher than mean value of Sirsa regarding infrastructure and equipment facilities for sports person. It is hereby stated that the infrastructure and equipment facilities for sports person in comparison to Sirsa and Bhiwani district, Bhiwani district is higher comparison to the Sirsa district.

Graph 5:

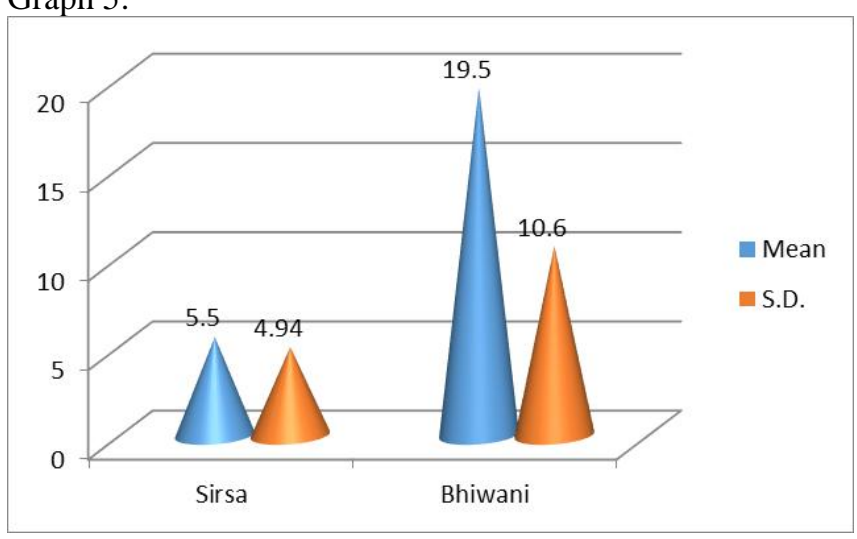

Table- VI: Comparison of total quality management (administration services) provided of sirsa and bhiwani districts

\begin{tabular}{|c|c|c|c|c|}
\hline Groups & Mean & S.D & S.E.D. & 't'-Ratio \\
\hline Sirsa & 8.00 & 5.63 & \multirow{2}{*}{2.68} & \multirow{2}{*}{$4.33^{*}$} \\
\cline { 1 - 3 } Bhiwani & 14.00 & 5.95 & & \\
\hline
\end{tabular}

Value of Significance at .01 level - 2.61

Value of Significance at .05 level -1.64

DF (Degree of Freedom) $\quad-118$

Total Sample (N) $\quad-120$

Table: 6represent the mean value of coaches and trainers opinion of administration services of Sirsa and Bhiwani district is 8.00 and 14.00respectively and the SD value of coaches and trainers opinion regarding administration services is5.63 and 5.95 respectively. The standard error difference is also find out with the reading of 2.68. The ' $t$ ' value is calculated as 4.33 , which is significant at .05 level of significance. Hence, hypothesis there is no noteworthy difference between coaches and trainers opinion of administration services of Sirsa and Bhiwani districts is rejected.

It is stated that mean value of Bhiwani district is 14.00 which is higher than mean value of Sirsa regarding administration services for sports person. It is hereby stated that the administration services for sports person in comparison to Sirsa and Bhiwani district, Bhiwani district is higher comparison to the Sirsa district.

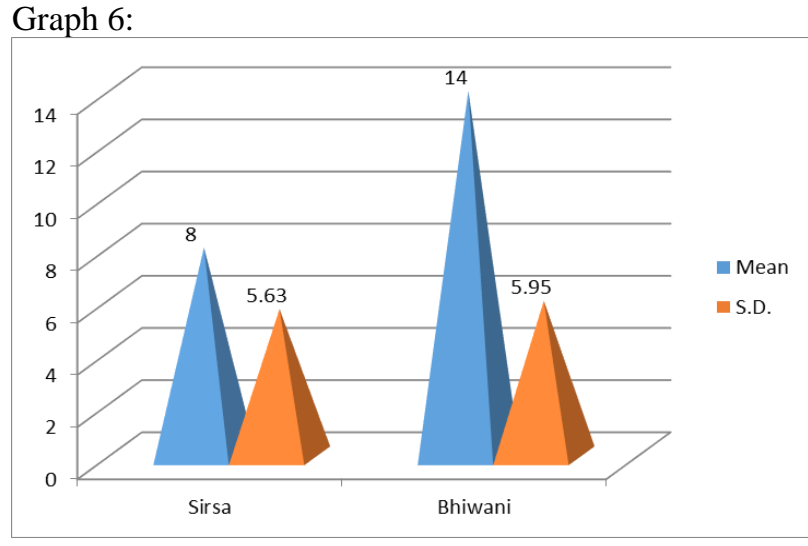

\section{CONCLUSION AND RESULTS}

From the above results it can be said that Bhiwani district is giving high level coaching quality, financial facility, health care services, food and nutrition services, infrastructure and equipment facilities, administrative servicesto their sports person in comparison to Sirsa. The ' $t$ ' value is calculated as 2.096, which is not substantial at .05 level of significance. Hence, there is no substantial difference between coaches and trainers opinion of coaching qualities provided of Sirsa and Bhiwani districts is accept.The ' $\mathrm{t}$ ' value is calculated as 3.28 , which is significant at .05 level of significance. Hence, hypothesis there is no substantial difference between coaches and trainers opinion of finance facilities of Sirsa and Bhiwani districts is rejected.The ' $t$ ' value is calculated as 3.21 which is greater than table value at .05 level of significance. Therefore, hypothesis there is no significant difference between coaches and trainers opinion of health care of Sirsa and Bhiwani districts is rejected.The ' $t$ ' value is calculated as 3.00, which is significant at .05 level of significance. Hence, hypothesis there is no substantial difference between coaches and trainers opinion of Food and nutrition of Sirsa and Bhiwani districts is rejected. The ' $t$ ' value is calculated as 3.50, which is significant at .05 level of significance. Hence, hypothesis there is no momentous difference between coaches and trainer's opinion of infrastructure and equipment facilities of Sirsa and Bhiwani districts is rejected. The ' $t$ ' value is calculated as 4.33, which is significant at .05 level of significance. Hence, hypothesis there is no substantial difference between coaches and trainer's opinion of administration services of Sirsa and Bhiwani districts is rejected.

\section{REFERENCES}

1. Arun Kumar Uppal, "Comparative Effect of Two Duration Load Methods and Interval Running Method on Cardio Respiratory Endurance and Selected Physiological Variables", (Unpublished Doctoral Dissertation, Jiwaji University, Gawalior, 1980).

2. AtinderaBarik, A.K. Banerjee, "Effect of 6 Week conditioning Programme on some performance variables between tribal and non tribal students", NIS Scientific Journal Vol. 17., No.2, 1994.

3. Gurdial Singh Bawa, KalpanaDebnath, "Effect of Six Week Training Camp on Physical Abilities Level of Elite Gymnasts" NIS Scientific Journal Vol. 17 No3. (1994)

4. M. Satayanarian, B.C. Kaushal, B. Singh, S. Singh, J. Singh and H Singh, in Journal of Sports and Sports Sciences, Vol. 25 (3): 42-46, 2002 . 
5. Simarjeet Singh, Jasmail Singh, Hardayal Singh, "Comparison of Physical Fitness Between Senior \& Junior Group of Hockey Girls," Journal of Sports and Sports Sciences, Vol. 26 (1) : 45-47, 2003.

6. Singh Pritpal: Effect of specific resistance exercise on selected passing and shooing techniques on basketball players. Unpublished Master's Thesis, NS NIS Patiala, 1982

7. T Mashiko, T Umeda, S Nakaji and K Sugawara (2004) British Journal Sports Medicine 2004; 38:186-190

8. U.S. Sharma, "A Comparative Study of the Effects of the Selected Training Programmes on Physical Fitness and General Motor Ability of Women Students" (Unpublished Doctoral Thesis, University of Delhi, 1980) 